\title{
The patient as experience broker in clinical learning
}

\author{
Lynette J. Stockhausen *
}

School of Nursing, University of Ballarat, P.O. Box 663, Ballarat, Victoria 3350, Australia

Accepted 23 June 2008

\section{Introduction}

It would be extraordinary for nurse education to consider learning nursing without patients. It is generally acknowledged that a patient's health problem, diagnosis, interventions, treatments and

\footnotetext{
Tel.: +6135327 9662; fax: +61353279719

E-mail address: l.stockhausen@ballarat.edu.au
}

outcomes provide the stimulus for the design and boundaries of clinical educative events.

The parameters of these clinical educative events are contextually bound by the patient and it "is the patient's needs which determine the nature of nursing's work' (Smith, 1987 p. 419) which in turn constitutes the teaching and learning events available to students. The patient's circumstances become the learning situation for students. However the active role the every-day patient, without 
formal teaching training from faculty, plays in contributing to learning encounters for students has received little substantial attention in nursing (Twinn, 1995; Suikkala and Leino-Kilpi, 2001, 2005; Mossop and Wilkinson, 2006; Trowle, 2006).

Of note are the many cursory remarks, made in texts and journal articles alike, of the importance of the patient to students' learning. For something that has been considered such an integral aspect of nursing education, research on the role of the patient in student's learning is surprisingly limited.

\section{Literature review}

As early as 1975, Infante noted that 'patient contact is the heart of student's activities' (p. 22) in the clinical setting. However, there is little known about what the patient thinks of these encounters. It was not until 2001 that Suikkala and Leino-Kilpi conducted a comprehensive review of the nursing literature from 1984 to 1998 on student patient relationships that some insights were gained. This is perhaps one of the most comprehensive reviews to date. Essentially, the review highlights patients' experiences and perceptions of their role in student learning and of the student's involvement in their care.

Of the limited number of relevant papers reviewed (approximately 10), by Suikkala and Leino-Kilpi (2001), they found that patients were willing to participate in students' learning to assist them gain experience and move towards becoming qualified. However, beyond participation Stacy and Spencer (1999) also revealed that patients found satisfaction in helping students. Patients providing feedback and encouragement to students were also determined beneficial to the learning experience (Suikkala and Leino-Kilpi, 2001).

Through social interactions patients also considered that students gained knowledge of the patient's experience from the patient's perspective (Suikkala and Leino-Kilpi, 2001; Lathlean et al., 2006). Spencer et al. (2000, p. 853) clearly indicate that "patients see themselves as experts in their own condition (both in terms of telling and showing), as exemplars of the condition (intuitively, perhaps, recognizing the importance of 'illness scripts') and as having a hand in the development of professional skills and attitudes".

A later study by Costello and Horne (2001) reached similar conclusions and also suggested that interpersonal engagement can also be therapeutic for the patient. Wykurz and Kelly's (2002) system- atic review of descriptions, evaluations or research programs involving patients as teachers in medical programs further established that the patient's involvement created a sense of empowerment and acknowledged their understanding and experience of their condition.

Continuing their original research, on patient and student relationships, Suikkala and Leino-Kilpi (2005), revealed some insight into the way patients perceive experienced clinicians (staff nurses) assist in the process of student learning. Suikkala and Leino-Kilpi (2005) reported that good role models, who offered supportive supervision and encouraging feedback to students, were essential to facilitate successful patient relationships. Furthermore, Stockhausen (2005) found that experienced clinicians are knowledgeable of patients' conditions and they can often detect learning events associated with the patient that the student may not yet notice. Access for the student is gained to this learning through the experienced clinician assigned to the care of the patient.

In recent years there has been a heightened interest in how patients, or how they are commonly referred to now in the literature, service users or consumers, participate in the education of nurses or other health care professionals (Trowle, 2006; Lathlean et al., 2006). However, many of these studies report on the use of trained patients and the everyday patient or service user is made little reference to.

While the above review offers some insight into the patient's role in student encounters there remains limited information on the patient's perceptions of their role in student's learning and of the student's involvement in the patient's care. Therefore, this study sought to investigate; what observations patients make of students involved in their care; how they perceive they assist student's learning to care and how patients perceive experienced clinicians assist students to learn how to care.

\section{The study}

As a qualitative study the research was an attempt to investigate the inter-subjectivity of how patients attribute meaning to their experiences. Carr and Kemmis highlight this point:

Actions cannot be observed in the same way as natural objects. They can only be interpreted by reference to the actor's motives, intentions and purposes in performing the action. To identify 
these motives and intentions correctly is to grasp the 'subjective meaning' the action has to the actor.

$$
\text { Carr and Kemmis, } 1986 \text { p. } 88
$$

As patients experience nursing care their interpretive reflections reveal what is significant for them. The significance is located in personal feelings and actions within the context of clinical nursing. In order to make visible the meanings embedded in these experiences, a research methodology is needed that both unearths taken for granted practices, but also develops an understanding of teaching and learning in clinical experiences. Qualitative research strategies provide the infrastructure to examine these subjective interpretations.

Taylor (1994, p. 235) indicates that "nursing is what happens between nurses and patients in the context of care". Therefore, as the recipient of care, it seemed appropriate that the patient was in the best position to comment about their observations and involvement in student learning.

Fourteen adult patients consented to participate in the study, four women and ten men. Suitable patients were only approached at the discretion of the attending nurse clinician and the unit manager (Charge Nurse). At the request of the hospital's ethics committee, patients involved in the study were required to successfully complete a Mental Status Questionnaire (MSQ) to determine their comprehension of involvement in the study. Participant patients gave written informed consent and were also given the opportunity to have a family member or friend present if they so desired. All patients involved had been assigned to the attending experienced nurse clinician and an undergraduate student in a Bachelor of Nursing program for a period of three to five days. Consent was also sought from the experienced clinician and the undergraduate students and their respective organisations.

A set of semi-structured questions were developed to focus the face-to-face patient interviews. The interview took place, with the author, in a private setting, was audio-taped and approximately $3050 \mathrm{~min}$ in duration. The posed questions were conversational in nature and allowed patients an opportunity to have their opinion acknowledged as important. The interviews permitted patients to talk about themselves, their illness and outcomes, demonstrating that while specific information was sought, interest in them as a person was maintained. Through the use of appropriate interpersonal skills and by creating a relaxed climate of trust, the researcher is less likely to have re- sponses of "don't know" (Polit et al., 2001). Face-to-face interviews also give the researcher an opportunity to judge the participant's degree of understanding and clarify misunderstandings if they arise.

The study was conducted in an acute care setting of a large Australian tertiary health institution. All care was taken to ensure confidentiality and anonymity of all concerned. Rigour was established in the study in a manner similar to that used by qualitative researchers (Polit et al., 2001). Dewey's (1933, p. 29) fundamental principles of reflection; open-mindedness; responsibility and wholeheartedness were adopted to represent rigour in the study.

\section{Review of the data}

Content analysis and the development of conceptual themes facilitate the presentation of the data. Word-processed files were generated from transcripts, allowing the researcher to read, reflect and develop ideas by reading the text. Through content analysis key descriptors were generated that helped examine responses to the research question. By combing the text, notation of key words, phrases or sentences became exposed, extracted and then were drawn together into similar threads.

Grouping of common threads represented a theme. These themes were then translated into a core category: 'Patients as experience Brokers'. The core category is supported by two themes: Patients as observers of teaching and learning to care and; Patients as participants in teaching to care.

\section{The findings}

\section{Patients as experience brokers}

The patient's audible voice acknowledges an aspect to teaching and learning in the clinical setting that has been relatively ignored. As a recipient of care and an integral feature in teaching and learning moments the research gave the patient a voice, recognizing them in the experience of being cared for by the experienced practitioner and student. The first theme to support the category 'Patients as experience brokers'; 'Patients as observers of teaching and learning to care', highlights patients' perceptions of, not only what they consider nursing to be but, also, how nursing is taught to the next generation of nurses. 


\section{Patients as observers of teaching and learning to care}

As an observer of teaching and learning to care, patients presented their views on what they perceived students did as learners of nursing to facilitate their restorative health. The students 'care for you if you are sick physically or in the mind'.

Revealed are a number of nursing activities that the patient considered highlighted nursing. These included; assessing, planning, evaluating care, assisting the patient with body hygiene, monitoring vital signs and treatments, attending to a diverse and sometimes complicated range of therapeutic regimes such as dressings and oxygen administration, dispensing and monitoring drug and intravenous therapies, accompanying patients to and from therapeutic, diagnostic and surgical procedures, conducting education sessions and communicating with patients, significant others and other health care professionals.

Patients were also asked what kinds of interactions they observed between the student and the experienced practitioner. The patients spoke of the experienced practitioner and student being friendly towards one another and co-operating together as they were cared for.

Interestingly, the patients spoke of how the experienced practitioner and student co-operated, shared nursing activities and talked generally about social, as well as, professional issues; 'all the staff seemed to create a relaxed and friendly atmosphere'.

Patients also considered that they were included in both social and professional interactions. Several stated that their opinion was sought and that they felt respected as a person. However, the majority of responses concentrated on qualities of the student and experienced practitioner that the patient perceived were beneficial to their care and all concerned. Responses regarding the student included: 'she had respect for me', 'was an attentive listener', 'asked me about how I would like to be involved in my care', 'appeared keen, willing to have a go' and 'the student consulted the nurse (experienced practitioner) about my care; nursing and science things'.

Patients also identified observations they made between students and experienced practitioners that they considered assisted student's learning. This included the experienced practitioner; demonstrating, offering information and suggestions regarding their care, asking students questions about the patient's care and observing them caring out nursing activities. Patients revealed that the experienced practitioner; 'talked a lot to the student, explaining what they were doing and why'; 'showed her how to do many things related to my care; made her aware of some situations'.

Experienced practitioners offered reassurances and constructive feedback and gave genuine and positive reinforcement whist monitoring student progress and directing them when necessary; 'the nurse (experienced practitioner) watched him do things and corrected him in an appropriate manner', 'she was a great teacher, usually jovial and never condescending, 'he was patient and knowledgeable with the student'.

In particular the patients felt that when the experienced practitioner 'treated the student as one of their own', 'showed she [the experienced practitioner] cared about me and the student' and 'included the student in my care' that the experienced practitioner was playing an active role in teaching the students to care as a nurse.

Significantly, the patients indicated that when a student appeared to be accepted as a member of the nursing team a co-operative teaching and learning nexus between patient, student and experienced practitioner was created.

\section{Patients as participants in teaching to care}

Alongside the first theme the second theme, 'Patients as participants in teaching to care', highlights the role patients consider they play in assisting students to become nurses. 'The students have to learn the practical, what nursing and caring are. It's first hand knowledge of people, their sickness and their problems'. Revealed is how patients offer themselves unconditionally to be part of the student's learning experience. Comments such as 'just being here for them to practice helps them', 'they need experience with and of people to practice their best and an encounter of being helped is a marvellous experience' were common. A majority of responses also centred on the patient co-operating with the student and offering praise and encouragement. 'Sometimes they take a little bit longer, or it causes you a little more discomfort but you tell them they are doing a really good job, they have to learn and I feel as if I'm helping to be part of that learning for them'.

Further explanations of co-operation by patients to assist student's learning included sharing aspects of themselves such as their medical and personal histories. 'I told her things about my life and problems with my health that I thought would help her learning, like.... to understand what it is like for me to have to struggle to breath'. 
The patients' responses confirm that as the recipient of care, the patient is aware of positive teaching and learning qualities. The patients offered themselves, as not only a learning resource but, in some cases used sophisticated facilitative teaching methods; 'I told her she was doing a wonderful job', 'that the injection was one of the best that I had had and that it didn't hurt', 'I showed her how I usually ...', ' ' explained why I do it this way...'

Patients highlighted concerned for the students' learning and in a sense developed empathy for the student and attempted to facilitate the students' learning experience. Even with no explicit training, patients appear to understand how they can appropriately facilitate students learning.

The patients' insights regarding their perceived interactions with students and between the students and the experienced practitioner, demonstrates that the patient is much more significant and insightful regarding clinical teaching and learning events, than they are given credit for. The interviews and ensuing interpretation significantly highlight that the patient acts as an experience broker positioning themselves in a unique learning triad, offering themselves to the experienced practitioner and student as a resource; a position not previous identified in clinical nursing educational research.

\section{Discussion}

The patient as experience broker adds a new dimension to understanding the way in which students learn in the clinical environment. As an experience broker the patient becomes an intermediary who brings parties together for specific purposes. In this research the patient mediates the teaching and learning experience between the experienced practitioner and the student.

Significantly the patient does not just expect a standard of care from experienced nurses but is willing to offer themself as a resource for learning and offer encouragement to students. The patient projects trust and confidence to the student as the student develops skill acquisition. What is highlighted is the way the patient is aware of the endearing qualities the experienced nurse extends to students as they induct students into the profession. These results are not dissimilar to previous studies reporting that patients have a strong commitment to assist students to gain experience in their preparation for practice (Twinn, 1995; Morgan and Sanggaran, 1997; Spencer et al., 2000; Suikkala and Leino-Kilpi, 2005).
Patients as people (Kotecki, 2002), their health conditions and status are a rich source for use in learning episodes for the experienced clinician and student. In the practice of nursing, the patient embodies and permeates the student's learning experience. For it is only through the exposure to the patient and all that they present that the student learns nursing. The learning is through the patient.

As an educative triad between student, experienced practitioner and patient it is the patient, along with their condition and the interactions they establish to assist learning that is pivotal. The patient's views bring a different perspective on what occurs as learning and teaching in the clinical setting.

\section{Study limitations}

A limited number of responses, fourteen, may diminish the validity of the patient response. Conversely, the vulnerability of the patient and their condition may have biased their responses. However, this did not appear to be the case when listening to the intent and voice inflections expressed in the patient's concerned responses during the interviews. No responses highlighted possible adverse effects of patient involvement in student's learning encounters. Indeed patients were more than willing to have students care for them and talk of their encounters.

\section{Conclusion}

This paper offers a perspective not previously highlighted. This is because, as the recipient of the teaching and learning, the patient validates the ways in which caring is established as the experienced clinician teaches and the student learns the practice of nursing in the authentic setting. As both an observer and participant in teaching and learning moments, with students and staff, the patient becomes an experience broker. As accidental teachers patients could be considered the principle source of the student's learning experience. They become the originator and the mediator through which teaching and learning moments occur between themselves, the student and registered nurse.

It is recommended that more precise descriptors on the engagement of the different types of patients involved in student learning encounters, including benefits and possible disadvantages, are required. The generation of a new educational per- 
spective (andragogy) of patients as teachers (experience brokers) in the future education of nurses as well as other health care professionals warrants further thought and considered investigation.

\section{Acknowledgements}

This paper was originally presented at the Nurse Education Tomorrow Conference, September 2007, Cambridge, UK. I thank those who offered their critical comment to refine and extend my thoughts for this paper and future research possibilities.

\section{References}

Costello, J., Horne, M., 2001. Patients as teachers? An evaluative study of patients' involvement in classroom teaching. Nurse Education in Practice 1 (2), 94102.

Dewey, J., 1933. How we think, Revised ed. D.C. Heath, Boston. Infante, M.S., 1975. The Clinical Laboratory in Nursing Education. Wiley and Sons, New York.

Lathlean, J., Burgess, A., Coldham, T., Gibson, C., Herbert, L., Levett-Jones, T., Simons, L., Tee, S., 2006. Experiences of service users and care participation in health care education. Nurse Education in Practice 6 (6), 424429.

Carr, W., Kemmis, S., 1986. Becoming Critical: Knowing Through Action Research. Deakin University Press, Melbourne.

Kotecki, C., 2002. Baccalaureate nursing students' communication process in clinical settings. Journal of Nursing Education 44 (2), 6168.

Morgan, S., Sanggaran, R., 1997. Client centred approach to student nurse education in mental health practicum: an inquiry. Journal of Psychiatric and Mental Health Nursing 4 (6), 423434.

Mossop, M., Wilkinson, T., 2006. Nursing education in gerontological clinical settings. What do elderly patients think of student-rendered care? Journal of Gerontological Nursing 32 (6), 49 55, June.

Polit, D., Beck, C., Hungler, B., 2001. Essentials of Nursing Research: Methods, Appraisal and Utilization, fifth ed. Lippincott, Philadelphia.

Smith, P., 1987. The relationship between quality of nursing care and the ward as a learning environment: developing a methodology. Journal of Advanced Nursing 12 (2), 413420.

Spencer, J., Blackmore, D., Heard, S., McCrorie, P., McHaffie, D., Scherpbier, A., Tarun, S.G., Singh, K., Southgate, L., 2000. Patient-orientated learning: a review of the role of the patient in the education of medical students. Medical Education 34 (10), 851857.

Stacy, R., Spencer, J., 1999. Patients as teachers: a qualitative study of patients' views on their role in a community based undergraduate project. Medical Education 33 (9), 688694.

Stockhausen, L., 2005. Learning to become a nurse: student's reflections on their clinical experiences. Australian Journal of Advanced Nursing 22 (3), 8 14, March May.

Suikkala, A., Leino-Kilpi, H., 2001. Nursing student-patient relationship: a review of the literature from 1984 to 1998. Journal of Advanced Nursing 33 (1), 4250.

Suikkala, A., Leino-Kilpi, H., 2005. Nursing student-patient relationship: experiences of students and patients. Nurse Education Today 25 (5), 344354.

Taylor, B., 1994. Being Human: Ordinariness in Nursing. Churchill Livingstone, Melbourne.

Trowle, A., 2006. Where's the patients voice in health education? Nurse Education in Practice 6 (5), 300302.

Twinn, S., 1995. Creating reality of contributing to confusion? An exploratory study of client participation in student learning. Nurse Education Today 15 (4), 291297.

Wykurz, G., Kelly, D., 2002. Developing the role of patients as teachers: literature review. British Medical Journal 325 (736), 818 821, October. 